tài trợ bởi Tập đoàn Vingroup - Công ty CP và hỗ trợ bởi chương trình học bổng đào tạo thạc sĩ, tiến sĩ trong nước của Quỹ Đổi mới sáng tao Vingroup (VINIF), Viện Nghiên cứu Dữ liệu lớn (VinBigdata), mã số VINIF.2020.ThS.61.

\section{TÀl LIÊU THAM KHẢO}

1. Sarkut P, Kilicturgay $\mathbf{S}$, Ozer A et al. Gallbladder polyps: factors affecting surgical decision. World J Gastroenterol. 2013;19(28): 4526-4530.

2. Salmenkivi $\mathbf{K}$ et al. Cholesterosis of the gall-bladder. A clinical study based on 269 cholecystectomies. Acta chir scand suppl. 1964;105(324):1-93.

3. Yiping $\mathbf{L}$, Talar $\mathbf{T}$ et al. Gallbladder polyps: real or imagined?. The American Surgeon. 2018;84(10): 1670-1674

4. Taskin OC, Basturk O, Reid MD et al. Gallbladder polyps: Correlation of size and clinicopathologic characteristics based on updated definitions. PLoS One. 2020;15(9):e0237979.

5. Roa I, de Aretxabala $X$, Morgan $R$, et al. Pólipos y adenomas de la vesícula biliar: consideraciones clínico-patológicas [Clinicopathological features of gallbladder polyps and adenomas]. Rev Med Chil. 2004;132(6):673-679.

6. Ryol LS, Ook HK, Ho JS. Reasonable cholecystectomy of gallbladder polyp-10 years of experience.Asian journal of surgery. 2019: 332-337.

7. BhattNR, GillisA, SmootheyCOet al. Evidence based management of polyps of the gall bladder: A systematic review of the risk factors of malignancy. Surgeon. 2016;14(5):278-86.

8. Wennmacker SZ, DijkAH, RaessensJHet al. Polyp size of $1 \mathrm{~cm}$ is insufficient to discriminate neoplastic and non-neoplastic gallbladder polyps. Surg Endosc. 2019;33(5):1564-1571.

9. Kyung SJ et al. Management strategies for gallbladder polyps: is it possible to predict malignant gallbladder polyps? Gut Liver. 2008;2(2):88-94.

\title{
MỐI LIÊN QUAN GIỮA NỒNG Độ DOPAMIN HUYÊT TƯO'NG VỚI MộT Số ĐẶC ĐIỂM LÂM SÀNG Ở BÊ̂NH NHÂN TRÂM CẢM CHỦ YẾU
}

\author{
Cao Văn Hiệp*, Đỗ Xuân Tĩnh*, \\ Nguyễn Văn Linh*, Đinh Việt Hùng*, Phạm Thị Thu*
}

\section{TÓM TẮT}

Mục tiêu: Khảo sát mối liên quan giữa nồng độ Dopamin huyết tương với một số đặc điêm lâm sàng ở bệnh nhân trầm cảm chủ yếu. Đối tượng và phương pháp nghiên cứu: Tiến cứu, mô tả cắt ngang trên nhóm bệnh gồm 62 bệnh nhân trầm cảm chủ yếu điều tri nội trú tại Khoa Tẩm thần, bênh viên Quân y 103. Nhóm chứng gồm 31 người khỏe mạnh có sự tương đồng về tuối và giới tính với nhóm bệnh. Kêt quả: Tỷ lệ nam giới ở nhóm nghiên cứu nhiều hơn nữ giới, tuy nhiên sự khác biệt không có ý nghĩa thống kê. Tuồi trung bình của nhóm bệnh và nhóm chứng lần lượt là $38,76 \pm 13,20$ và $39,71 \pm 14,27$; sự khác biệt cũng không có ý nghĩa thống kê với $p>0,05$. Nồng độ Dopamin huyết tương ở nhóm bệnh nhân trầm cảm $(24,96 \pm 12,55 \mathrm{pg} / \mathrm{ml})$ thấp hơn nhóm chứng $(28,72 \pm 11,95 \mathrm{pg} / \mathrm{ml})$, tuy nhiên khác biệt không có ý nghĩa thống kê với $p>0,05$. Nồng độ Dopamin huyết tương ở đối tượng nghiên cứu (nhóm bệnh và nhóm chứng) khác biết không có ý nghĩa thống kê theo giới tính và độ tuổi. Nồng độ Dopamin huyết tương ở nhóm bênh nhân trầm cảm chủ yếu có loạn thần thấp hơn nhóm trầm cảm không có loạn thần, sự khác biệt không có ý nghĩa thống kê $(18,26 \pm 13,32 \mathrm{pg} / \mathrm{ml}$ và $25,68 \pm 12,38 \mathrm{pg} / \mathrm{ml}$, với $\mathrm{p}>0,05)$. Không tồn tại mối liên quan giữa nồng độ Dopamin huyết tương với điểm

*Bệnh viện Quân y 103

Chịu trách nhiệm chính: Cao Văn Hiệp

Email: hatcat275@gmail.com

Ngày nhận bài: 16.9.2021

Ngày phản biên khoa họ: 12.11.2021

Ngày duyệt bài: 24.11.2021
Beck ở nhóm bệnh nhân nghiên cứu. Kết luận: Nồng độ Dopamin huyết tương ở nhóm bệnh nhân trâm cảm chủ yếu ít biến đổi so với nhóm chứng. Nồng độ Dopamin huyết tương ở bệnh nhân trầm cảm chủ yếu không phụ thuộc vào giới tính, tuổi, triệu chứng loạn thần và điểm trắc nghiệm Beck.

Tư khóa: nồng độ Dopamin huyết tương, trâm cảm chủ yếu.

\section{SUMMARY \\ CORRELATION BETWEEN PLASMA CONCENTRATIONS OF DOPAMINE AND SOME CLINICAL PARAMETERS IN PATIENTS WITH MAJOR DEPRESSIVE DISORDER}

Objective: To investigate the correlation between plasma concentrations of Dopamine and some clinical parameters in patients with major depressive disorder. Subjects and Methods: Descriptive cross-sectional study in a patient group of 62 inpatients with major depression treated at the Department of Psychiatry, Military Hospital 103. A control group consisted of 31 healthy participants whose sex and age were similar to the group of patients. Results: The proportion of male subjects was higher than that of female ones, but the difference was not statistically significant. The mean ages in the patients and the controls were $38.76 \pm 13.20$ and $39.71 \pm 14.27$, respectively; the gap was still insignificant, with $p>0.05$. The mean concentrations of Plasma Dopamine in the group of patients was $(24.96 \pm 12.55 \mathrm{pg} / \mathrm{ml})$ lower than the figure for the group of controls $(28.72 \pm 11.95 \mathrm{pg} / \mathrm{ml})$; However, the disparity was not statistically considerable, with $p>0.05$. Dopamine levels in plasma in the subjects (both the patient group and the control 
group) insignificantly differed by sex and age. The depressed patients with psychotic features had lower levels of plasma Dopamine than the patients without psychosis; the difference was not statistically significant $(18.26 \pm 13.32 \mathrm{pg} / \mathrm{ml}$ and $25.68 \pm 12.38$ $\mathrm{pg} / \mathrm{ml}$, with $\mathrm{p}>0.05)$. There was no correlation between plasma concentrations of Dopamine and Beck depression inventory scores. Conclusion: The study showed the concentrations of Plasma Dopamine in depressed patients changed insignificantly to the figures for the controls. Furthermore, the Dopamine levels in plasma in the depressed patients did not depend on sex, age, psychotic features, and Beck depression inventory scores.

Keywords: plasma concentrations of Dopamine, major depressive disorder.

\section{I. ĐĂT VẤN ĐỀ}

Trầm cảm chủ yễu là một rối loạn cảm xúc phổ biến, theo Hội Tâm thần học Mỹ (2013), tỷ lệ mắc trầm cảm trong 12 tháng ở Mỹ là $7 \%$ dân số và $1,5 \%$ dân số Mỹ có đủ tiêu chuẩn chẩn đoán cho trầm cảm mạn tính [1]. Bệnh sinh của rối loạn trầm cảm rất phức tạp, trong đó sự thay đổi của nồng độ các chất dẫn truyền thần kinh trung ương như Serotonin, Norepinephrin, Dopamin... được coi là đóng vai trò quan trọng. Sự thay đổi nồng độ của các chất dẫn truyền thần kinh trung ương cũng như các sản phẩm chuyển hóa của chúng được tìm thấy không chỉ trong tổ chức não, dịch não tủy, mà còn có thể xảy ra ở máu ngoại vi [2].

Mất hứng thú sở thích là một triệu chứng chính của rối loạn trầm cảm chủ yếu và hệ thống Dopaminergic đóng vai trò quan trọng trong triệu chứng này. Catecholamin được sinh tổng hợp từ Tyrosin ở tuỷ thượng thận, các neuron hậu hạch giao cảm và một số neuron của thần kinh trung ương theo trình tự:

Tyrosin $\rightarrow$ L-DOPA $\rightarrow$ Dopamin $\rightarrow$ Norepinephrin $\rightarrow$ Epinephrin

Sau khi hoàn thành các tác động, Dopamine được chuyển hóa thành Homovanillic acid (HVA) lưu hành trong máu rồi thải trừ theo nước tiểu. Nồng độ tự do của Dopamin tăng khi có kích thích cường giao cảm. Do đó, vận động nhiều hay một số phản ứng cảm xúc căng thẳng, lo lắng có thể gây tăng nồng độ Dopamin huyết tương [3].

Tại Việt Nam chưa có nhiều nghiên cứu về nồng độ Dopamin trong máu ở bệnh nhân trầm cảm chủ yếu với một số đặc điểm lâm sàng liên quan. Do đó, chúng tôi thực hiện nghiên cứu nhằm khảo sát nồng độ Dopamin huyết tương với một số đặc điểm lâm sàng ở bệnh nhân trầm cảm chủ yếu.

\section{II. ĐỐI TƯợNG VÀ PHƯƠNG PHÁP NGHIÊN CỨU}

\section{1. Đối tượng nghiên cứu.}

- Nhóm bệnh: 62 bệnh nhân trầm cảm chủ yếu theo tiêu chuẩn của Hội Tâm thần học Mỹ (DSM-5), điều trị nội trú tại khoa Tâm thần-Bệnh viện Quân y 103 từ tháng 8 năm 2020 đến tháng 7 năm 2021.

- Nhóm chứng: 31 người khỏe manh có sự tương đồng về giới tính và tuổi so với nhóm bệnh.

\subsection{Phương pháp nghiên cứu}

- Thiết kễ nghiên cứu: tiến cứu, mô tả cắt ngang.

- Tiến hành nghiên cứu: Khám lâm sàng, kết hợp trắc nghiệm Beck trên bệnh nhân nghiên cứu lúc vào viện. Xét nghiệm định lượng nồng độ Dopamin huyết tương khi nghỉ ngơi buổi sáng (6 giờ - 8 giờ) ở nhóm chứng và nhóm bệnh nhân trầm cảm chủ yếu (trong vòng 3 ngày đầu nhập viện).

- Định lượng nồng độ Dopamin huyết tương theo phương pháp sắc ký lỏng hiệu năng cao tại Bộ môn Khoa Sinh lý bệnh - Học Viện Quân y.

- Trị số nồng độ Dopamin huyết tương và điểm Beck được thể hiện bằng giá trị trung bình với độ lệch chuẩn (Mean $\pm S D)$, trung vị và trị số phân vị thứ 25\%, 75\% (Median (TPV 25;75)). Xử lí số liệu bằng SPSS 20.0.

\section{KẾT QUẢ NGHIÊN CỨU}

\section{1. Đặc điểm chung của nhóm nghiên cứu}

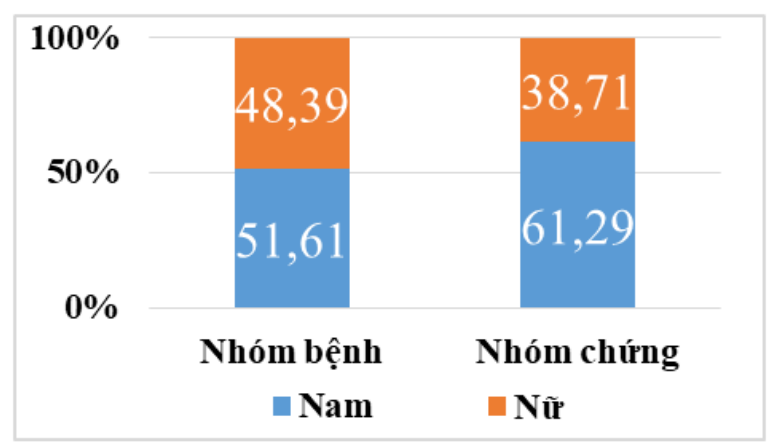

\section{Biểu đồ 3.3. Phân bố nhóm nghiên cứu theo giới tính}

Nhận xét: Trong nhóm bệnh, tỷ lệ nam trầm cảm $(51,61 \%)$ nhiều hơn nữ trầm cảm (48,39\%), tuy nhiên sự khác biệt không có ý nghĩa thống kê với $p>0,05$. Tương tự, ở nhóm chứng, tỷ lệ nam giới $(61,29 \%)$ cũng nhiều hơn nữ giới $(38,71 \%)$, nhưng sự khác biệt cũng không có ý nghĩa thống kề với p>0,05. Như vậy, nhóm chứng và nhóm bệnh có sự tương đồng với nhau về tỷ lệ giới tính (kiểm định Chi-square). 
Bảng 3.16. Phân bố nhóm nghiên cứu theo tuổi

\begin{tabular}{|c|c|c|c|c|}
\hline \multirow{2}{*}{ Nhóm tuổi Nhóm nghiên cứu } & \multicolumn{2}{|c|}{ Nhóm bệnh (n=62) } & \multicolumn{2}{|c|}{ Nhóm chứng (n=31) } \\
\hline & $\mathbf{n}$ & $\%$ & $\mathbf{n}$ & $\%$ \\
\hline$\leq 20$ & 7 & 11,29 & 1 & 3,23 \\
\hline $21-30$ & 13 & 20,97 & 10 & 32,26 \\
\hline $31-40$ & 13 & 20,97 & 6 & 19,35 \\
\hline $41-50$ & 17 & 27,42 & 6 & 19,35 \\
\hline$>50$ & 12 & 19,35 & 8 & 25,81 \\
\hline Tuổi trung bình (năm) & \multicolumn{2}{|c|}{$38,76 \pm 13,20$} & \multicolumn{2}{|c|}{$39,71 \pm 14,27$} \\
\hline
\end{tabular}

Nhận xét: Tuổi trung bình của nhóm bệnh và nhóm chứng lần lượt là $38,76 \pm 13,20$ và

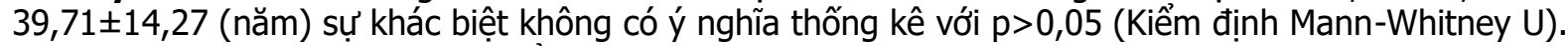
Nhóm chứng và nhóm bệnh có tuổi trung bình tương đương.

3.2. Nồng độ Dopamin huyết tương ở nhóm nghiên cứu

Bảng 3.17. Nồng độ trung binh Dopamin

\begin{tabular}{|c|c|c|}
\hline Nhóm Chí số & Mean \pm SD $(\mathbf{p g} / \mathbf{m l})$ & Trung vị (TPV 25;75) \\
\hline Bệnh nhân $(\mathrm{n}=62)$ & $24,96 \pm 12,55$ & $22,60(19,02 ; 31,13)$ \\
\hline Chứng $(\mathrm{n}=31)$ & $28,72 \pm 11,95$ & $26,71(20,71 ; 37,33)$ \\
\hline $\mathbf{p}$ & & $>0,05$ \\
\hline
\end{tabular}

Nhận xét: nồng độ trung bình Dopamin huyết tương ở nhóm bệnh nhân trầm cảm (24,96 12,55 $\mathrm{pg} / \mathrm{ml})$ thấp hơn nhóm chứng $(28,72 \pm 11,95 \mathrm{pg} / \mathrm{ml})$, nhưng sự khác biệt không có ý nghĩa thống kê với $p>0,05$.

Bảng 3.18. Nồng độ Dopamin theo giới tính

\begin{tabular}{|c|c|c|c|c|c|c|}
\hline \multicolumn{2}{|c|}{ Nhóm Chỉ số } & \multicolumn{4}{|c|}{$\begin{array}{l}\text { Mean } \mathbf{\pm S D}(\mathbf{p g} / \mathbf{m l}) \\
\text { Trung vị (TPV } 25 ; 75) \\
\end{array}$} & $\mathbf{p}$ \\
\hline \multirow{2}{*}{ Bệnh } & $\operatorname{Nam}(n=32)$ & 26,74 & 14,$10 ; 23,2$ & $(18,81 ; 34,95)$ & & \multirow{2}{*}{$>0,05$} \\
\hline & Nữ $(n=30)$ & 23,07 & 10,$58 ; 21,6$ & $(18,46 ; 28,18)$ & & \\
\hline \multirow{2}{*}{ Chứng } & $\operatorname{Nam}(n=19)$ & 29,17 & 11,$50 ; 24,3$ & $(20,71 ; 38,68)$ & & \multirow{2}{*}{$>0,05$} \\
\hline & Nũ $(n=12)$ & 28,01 & 13,$13 ; 27$ & $(20,62 ; 34,18)$ & & \\
\hline \multirow{2}{*}{\multicolumn{3}{|c|}{$\begin{array}{l}\text { Nhận xét. Nồng độ trung bình Dopamin } \\
\text { huyết tương ở nữ trầm cảm }(23,07 \pm 10,58 \\
\mathrm{pg} / \mathrm{ml}) \text { thấp hơn nam trầm cảm }(26,74 \pm 14,10\end{array}$}} & \multirow[t]{2}{*}{ Dopamin } & $\begin{array}{l}\text { Hệ số tương } \\
\text { quan }(r)\end{array}$ & 0,07 & $-0,13$ \\
\hline & & & & $p$ & 0,72 & 0,32 \\
\hline
\end{tabular}

$\mathrm{pg} / \mathrm{ml})$, tuy nhiên sự khác biệt không có ý nghĩa thống kê với $p>0,05$. Ở nhóm chứng, nồng độ Dopamin huyết tương của nam và nữ là tương đương nhau $(29,17 \pm 11,50$ và $28,01 \pm 13,13$ $\mathrm{pg} / \mathrm{ml}, \mathrm{p}>0,05)$.

Nồng độ Dopmin huyết tương lúc vào viện ở nam trầm cảm $(26,74 \pm 14,10 \mathrm{pg} / \mathrm{ml})$ thấp hơn nam nhóm chứng $(29,17 \pm 11,50 \mathrm{pg} / \mathrm{ml})$; kết quả tương tự, ở nữ trầm cảm $(23,07 \pm 10,58 \mathrm{pg} / \mathrm{ml})$ thấp hơn nữ nhóm chứng $(28,01 \pm 13,13 \mathrm{pg} / \mathrm{ml})$. Tuy nhiên sự khác biệt đều không có ý nghĩa thống kê với $p>0,05$. Như vậy, nồng độ Dopamin huyết tương ở nhóm nghiên cứu (bệnh và chứng) theo giới tính khác biệt không có ý nghĩa thống kê.

Bảng 3.19. Tương quan giứa nồng độ Dopamin huyêt tương và tuối

\begin{tabular}{|l|l|l|}
\hline \multirow{2}{*}{ Nhóm nghiên cứu } & \multicolumn{2}{|c|}{ Tuối } \\
\cline { 2 - 3 } Chî số & $\begin{array}{l}\text { Nhóm } \\
\text { chứng } \\
(\mathrm{n}=31)\end{array}$ & $\begin{array}{c}\text { Nhóm } \\
\text { beệnh } \\
(\mathrm{n}=62)\end{array}$ \\
\hline
\end{tabular}

Nhận xét: Tương quan giữa nồng độ Dopamin huyết tương với tuổi ở nhóm bệnh nhân trầm cảm chủ yểu tồn tại không có ý nghĩa thống kê $(p=0,32)$. Kết quả tương tự ở nhóm chứng với $\mathrm{p}=0,72$.

Bảng 3.20. Nồng độ Dopamin theo triệu chứng loạn thần ở nhóm bệnh nhân

\begin{tabular}{|c|c|c|}
\begin{tabular}{|c|c|} 
Triệu chứng \\
Coạn thần
\end{tabular} & $\begin{array}{c}\text { Mean } \pm \text { SD } \\
\text { (pg/ ml) }\end{array}$ & $\begin{array}{c}\text { Trung vị } \\
\text { (TPV 25;75) }\end{array}$ \\
\hline $\begin{array}{c}\text { Không loạn } \\
\text { thần (n=56) }\end{array}$ & $25,68 \pm 12,38$ & $\begin{array}{c}22,84 \\
(19,29 ; 32,74)\end{array}$ \\
\hline $\begin{array}{c}\text { Có loạn thần } \\
\text { (n=6) }\end{array}$ & $18,26 \pm 13,32$ & $\begin{array}{c}16,45 \\
(6,71 ; 27,42)\end{array}$ \\
\hline p & \multicolumn{2}{|c|}{$>0,05$} \\
\hline
\end{tabular}

Nhận xét: Nồng độ trung bình Dopamin huyết tương ở nhóm bệnh nhân trầm cảm có loạn thần $(18,26 \pm 13,32 \mathrm{pg} / \mathrm{ml})$ thấp hơn so với nhóm bệnh nhân trầm cảm không có loạn thần $(25,68 \pm 12,38 \mathrm{pg} / \mathrm{ml})$, sự khác biệt không có ý nghĩa thống kê với $p>0,05$. 


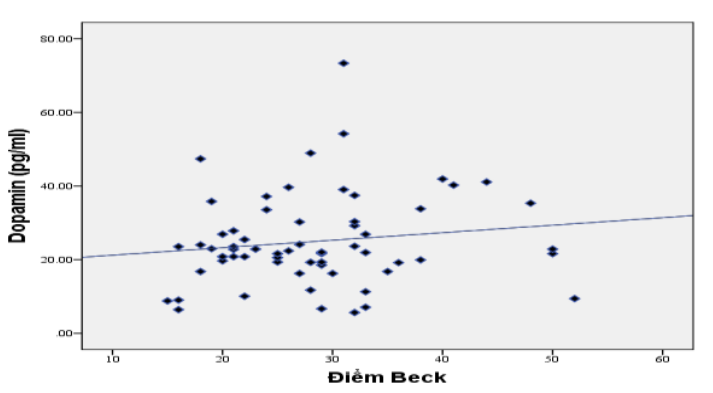

Biểu đồ 3. 4. Tương quan giữa nồng đô Dopamin huyêt tương và điểm Beck ở nhóm bệnh nhân trầm cảm chủ yếu

Nhận xét. Không tồn tại tương quan giữa điểm Beck với nồng độ Dopamin huyết tương ở bệnh nhân trầm cảm chủ yếu $(p=0,38)$.

\section{BÀN LUẬN}

4.1. Nồng độ Dopamin huyết tương ở nhóm nghiên cứu

4.1.1. Nồng độ trung bình. Nồng độ Dopamin huyết tương ở nhóm bệnh nhân trầm cảm $(24,96 \pm 12,55 \mathrm{pg} / \mathrm{ml})$ thấp hơn nhóm chứng $(28,72 \pm 11,95 \mathrm{pg} / \mathrm{ml})$, tuy nhiên khác biệt không có ý nghĩa thống kê với $p>0,05$.

Wyatt và cộng sự (1971) tiến hành nghiên cứu ở 13 bệnh nhân trầm cảm so với 47 người bình thường nhóm chứng thây nồng độ Catecholamin toàn phần (Epinephrin, Norepinephrin và Dopamin) trong huyết tương lúc nghỉ ngơi ở nhóm bệnh cao hơn đáng kể so với nhóm chứng [4]. Chúng tôi chỉ định lượng Dopamin nên cho kết quả nghiên cứu khác với tác giả. Dopamin có thể coi như là tiền chất của Norepinephrin và Epinephrin do đó việc định lượng toàn bộ Catecholamin có thể sẽ có kết quả thể hiện sự thay đổi rõ ràng hơn là chỉ định lượng riêng Dopamin.

Mazure và cộng sự (1987) tiến hành nghiên cứu trên 33 bệnh nhân trầm cảm nội trú (tuổi từ 24-85), toàn bộ là nữ giới, bao gồm trầm cảm chủ yếu $(n=15)$, trầm cảm có loạn thần $(n=8)$ và trầm cảm u sâu $(n=10)$. Mức độ trầm cảm được đánh giá bằng thang điểm CGI (Clinical Global Impression). Mẫu máu được thu thập vào buổi sáng của ngày hôm sau vào viện để đo nồng độ tự do trong huyết tương của HVA. Kết quả nghiên cứu thây trong số các bệnh nhân nghiên cứu (nữ) có HVA tự do huyết tương cao thì trầm cảm có loạn thần và trầm cảm u sầu cùng chiếm tỉ lệ tương đương nhau khoảng 45,45\%, cao hơn đáng kể so với $(9,09 \%)$ ở nhóm nhóm trầm cảm chủ yếu (không có loạn thần và u sầu). Độ tuổi có tương quan thuận với nồng độ HVA huyết tương $(r \approx 0,35 ; p \approx 0,04)$. Điểm CGI và nồng độ
HVA lúc vào viện có sự tương quan thuận chiêu yếu $(r \approx 0,15 ; p<0,05)$ [5]. Kết quả của Mazure và cộng sự (1987) so với kết quả nghiên cứu của chúng tôi có một số khác biệt:

+ Nghiên cứu của tác giả cho thấy tỉ lệ nồng độ HVA cao hơn ở bệnh nhân trầm cảm có loạn thần. Nghiên cứu của chúng tôi thấy nồng độ Dopamin huyết tương ở bệnh nhân trầm cảm có loạn thần là $18,26 \pm 13,32 \mathrm{pg} / \mathrm{ml}$ thấp hơn so với bệnh nhân trầm cảm không có loạn thần $(25,68 \pm 12,38 \mathrm{pg} / \mathrm{ml})$, tuy nhiên sự khác biệt không có ý nghĩa thống kê với p>0,05.

+ Tác giả nhận định độ tuổi có tương quan thuận với nồng độ HVA huyết tương. Nghiên cứu của chúng tôi thấy không có tương quan giữa tuổi và nồng độ $D A$ huyết tương ở nhóm bệnh nhân trầm cảm $(p=0,32)$.

+ Điểm CGI (mức độ trầm cảm) có tương quan thuận chiều yếu với nồng độ HVA huyết tương lúc vào viện $(r \approx 0,15 ; p<0,05)$. Nghiên cứu của chúng tôi thấy không tồn tại tương quan giữa mức độ trầm cảm (theo điểm Beck) với nồng độ $D A$ huyết tương $(r \approx 0,11 ; p \approx 0,38)$.

Sự khác nhau kết quả nghiên cứu của tác giả với nghiên cứu của chúng tôi do bất đồng về chất xét nghiệm (tác giả đo HVA, chúng tôi đo DA), bất đồng về tỉ lệ giới tính (nữ giới 100\% so với 48,39\%).

4.1.2. Nông độ Dopamin huyết tương theo giới tính. Nghiên cứu của chúng tôi cho thây nồng độ Dopamin huyết tương ở 2 nhóm nghiên cứu (nhóm chứng và nhóm bệnh) theo giới tính khác biệt không có ý nghĩa thống kê.

Devanand và cộng sự (1985) định lượng trong huyết tương nồng độ axit Homovanillic tự do (HVA) ở 29 bệnh nhân trầm cảm u sầu (DSMIII năm 1980) trước khi điêu trị so với 18 đối tượng nhóm chứng. Kết quả cho thây nồng độ HVA huyết tương tự do ở nữ nhóm bệnh cao hơn đáng kể so với nữ nhóm chứng và nam nhóm bệnh [6]. Kết quả của chúng tôi không phù hợp với nghiên cứu của Devanand và cộng sự (1985), sự khác biệt này là dễ hiểu bởi phương pháp đo của 2 nghiên cứu là khác nhau. Chúng tôi đo nồng độ Dopamin huyết tương, còn Devanand và cộng sự (1985) đo sản phẩm chuyển hóa của Dopamin là HVA, tữ đó ngoại suy nồng độ Dopamin.

\subsubsection{Nồng độ Dopamin huyết tương} theo triệu chứng loạn thân. Có nhiều bằng chứng cho thấy cường Dopaminergic gắn liền với các triệu chứng hưng cảm và loạn thần [3].

Hamner và Diamond (1996) khảo sát ở 12 bệnh nhân nam nội trú đáp ứng các tiêu chí về giai đoạn trầm cảm chủ yếu không loạn thần. 
Mức độ trầm cảm được đánh giá bằng thang điểm Hamilton (Hamilton Rating Scale for Depression: HRSD). Nghiên cứu cho thấy nồng độ Dopamin trong huyết tương có tương quan thuận chiều đáng kể với tổng điểm thang HRSD $(r=0,79 ; p<0,01)$, qua đó cho thấy nồng độ $D A$ huyết tương có thể phản ánh mức độ trầm trọng của chứng trầm cảm [7].

Nghiên cứu của chúng tôi trên 62 bệnh nhân trầm cảm, trong đó có 6 trường hợp (chiếm $9,68 \%$ ) có triệu chứng loạn thần và tỉ lệ nam giới chiếm $51,61 \%$, sử dụng thang điểm Beck (BDI) để khảo sát thay đổi mức độ trầm cảm, kết quả thấy không tồn tại tương quan giữa nồng độ Dopamin huyết tương với giá trị điểm Beck tương ứng. Như vậy nghiên cứu của chúng tôi không phù hợp với tác giả Hamner và Diamond (1996) vì khônng đồng nhất các đặc điểm của mẫu nghiên cứu như tî lệ nam giới (100\% so với $51,61 \%)$, tỉ lệ có loạn thần ( $0 \%$ so với $9,68 \%)$ và thang đánh giá trầm cảm (HRSD so với $\mathrm{BDI}$ ).

Một số nghiên cứu gần đây cho thãy chỉ khoảng 40\% nồng độ HVA trong huyết tương có nguồn gốc từ chuyển hóa Dopamin trong hệ thần kinh trung ương, đây là căn cứ lý giải cho sự khác biệt giữa kết quả nghiên cứu của chúng tổi với nghiên cứu của các tác giả trên [8].

\section{KẾT LUÂ̂N}

- Nồng độ Dopamin huyết tương ở nhóm bệnh nhân trầm cảm chủ yếu thấp hơn so với nhóm chứng, nhưng sự khác biệt không có ý nghĩa thống kê $(24,96 \pm 12,55 \mathrm{pg} / \mathrm{ml}$ và $28,72 \pm 11,95 \mathrm{pg} / \mathrm{ml}, \mathrm{p}>0,05)$. Nồng độ Dopamin huyết tương ở nhóm bệnh nhân trầm cảm chủ yễu có loạn thần $(18,26 \pm 13,32 \mathrm{pg} / \mathrm{ml})$ thấp hơn so với nhóm trầm cảm không có loạn thần $(25,68 \pm 12,38 \mathrm{pg} / \mathrm{ml})$, sự khác biệt cũng không có ý nghĩa thống kê với p $>0,05$.

- Nồng độ Dopamin huyết tương ở nhóm nghiên cứu (nhóm bệnh và nhóm chứng) không phụ thuộc vào giới tính và độ tuổi.

- Không tồn tại tương quan giữa nồng độ Dopamin huyết tương và điểm Beck ở nhóm bệnh nhân trầm cảm chủ yếu.

\section{TÀI LIÊU THAM KHẢO}

1. American Psychiatric Association, Diagnostic and Statistical manual of mental disorder, (2013), 155-188.

2. Gotlib I.H, Hammen C.L, Handbook of Depression, New York, (2009), 187-218.

3. Belujon P., Grace A. A. ,"Dopamine System Dysregulation in Major Depressive Disorders", Int J Neuropsychopharmacol, (2017), 20(12), 1036-1046.

4. Wyatt R. J., Portnoy B., Kupfer D. J. et al., "Resting plasma catecholamine concentrations in patients with depression and anxiety", Arch Gen Psychiatry, (1971), 24(1), 65-70.

5. Mazure C. M., Bowers M. B., Jr., Hoffman F., Jr. et al, "Plasma catecholamine metabolites in subtypes of major depression", Biol Psychiatry, (1987), 22(12), 1469-72.

6. Devanand D. P., Bowers M. B., Jr., Hoffman F. J., Jr. et al, "Elevated plasma homovanillic acid in depressed females with melancholia and psychosis", Psychiatry Res, (1985), 15(1), 1-4

7. Hamner M. B., Diamond B. I., "Plasma dopamine and norepinephrine correlations with psychomotor retardation, anxiety, and depression in non-psychotic depressed patients: a pilot study", Psychiatry Res, (1996), 64(3), 209-11.

8. Kendler K. S., Heninger G. R., Roth R. H. "Influence of dopamine agonists on plasma and brain levels of homovanillic acid", Life Sci, (1982), 30(24), 2063-9.

\section{NGHIÊN CỨU NỒNG Độ NT-proBNP HUYẾT THANH VÀ MỐI LIÊN QUAN VớI MỨC Độ TỔN THƯƠ'NG ĐộNG MACH VÀNH BẰNG THANG ĐIỂM SYNTAX II Ở BÊ̂NH NHÂN NHỒI MÁU CƠ TIM CẤP}

\section{TÓM TẮT}

\author{
${ }^{1}$ Học viện Quân y \\ ²Bệnh viện Đa khoa Hà Đông \\ ${ }^{3}$ Bênh viên Quân y 103 \\ Chiu trách nhiêm chính: Trần Đức Hùng \\ Email: tranduchung2104@gmail.com \\ Ngày nhận bài: 16.9.2021 \\ Ngày phản biện khoa học: 12.11.2021 \\ Ngày duyệt bài: 25.11.2021
}

\section{Lê Phước Trung ${ }^{1}$, Đỗ Hũu Nghị ${ }^{2}$, Trần Đức Hùng ${ }^{3}$}

Mục tiêu: Đánh giá nồng độ NT-proBNP huyết thanh và mối liên quan với mức độ tổn thương động mạch vành bằng thang điểm SYNTAX II ở bệnh nhân (BN) nhồi máu cơ tim (NMCT) cấp. Đối tượng và phương pháp nghiên cứu: Nghiên cứu mổ tả cắt ngang 69 BN được chẩn đoán xác định NMCT cấp được chụp động mạch vành (ĐMV) qua da tại Trung Tâm Tim mạch, Bềnh viên Quân y 103 từ tháng $1 / 2020$ đến tháng $6 / 2021$. Kết quả: Độ tuổi trung bình của nhóm nghiên cứu là $65,8 \pm 11,2$. Nam giới chiếm tỉ lệ cao (76,8\%). Giá trị trung vị của nồng độ NT-proBNP là 242,7 (Min 82,2; Max 871,5) pg/mi. 